\title{
Dalgıç ve Düşey Milli Derin Kuyu Pompalarında Bazı Pompaj Parametrelerinin Karşılaștırılması
}

\author{
Nuri Orhan ${ }^{1 *}$, Mehmet Kurt ${ }^{2}$ \\ ${ }^{1 *}$ Selçuk Üniversitesi Ziraat Fakültesi Tarım Makineleri ve Teknolojileri Mühendisliği Bölümü, Selçuklu, KONYA, Turkey, (ORCID: 0000-0002-9987-1695), \\ nuriorhan@selcuk.edu.tr \\ 2 Selçuk Üniversitesi Cihanbeyli Meslek Yüksekokulu Yönetim ve Organizasyon Bölümü, KONYA, Turkey, (ORCID: 0000-0002-9566-6627), \\ mehmet.kurt@selcuk.edu.tr
}

(İlk Geliş Tarihi 6 Temmuz 2021 ve Kabul Tarihi 6 Eylül 2021)

(DOI: 10.31590 /ejosat.963369)

ATIF/REFERENCE: Orhan, N., Kurt, M., (2021). Dalgı̨̧ ve Düşey Milli Derin Kuyu Pompalarında Bazı Pompaj Parametrelerinin Karşılaştırılması. Avrupa Bilim ve Teknoloji Dergisi, (27), 549-556.

\section{Öz}

Tarımsal sulama faaliyetleri yer altı ve yer üstü su kaynaklarından sağlanmaktadır. Yer altı su kaynaklarının yeryüzüne çıkarmak için dalgıç ve düşey milli olmak üzere iki tip derin kuyu pompası kullanılmaktadır. Çalışmada $150 \mathrm{~mm}\left(\mathrm{D}_{1}\right), 175 \mathrm{~mm}\left(\mathrm{D}_{2}\right)$ ve $200 \mathrm{~mm}\left(\mathrm{D}_{3}\right)$ dış çapa sahip dalgıç ve $150 \mathrm{~mm}\left(\mathrm{M}_{1}\right)$, $175 \mathrm{~mm}\left(\mathrm{M}_{2}\right)$ ve $200 \mathrm{~mm}\left(\mathrm{M}_{3}\right)$ dış çapa sahip milli tip derin kuyu pompalarının farklı debi değerlerinde kuyu su seviyesi düşümüne, gürültü seviyesine, şebekeden çekilen güce ve toplam dinamik yükseklik değerlerine etkileri karşılaştırılması amaçlanmıştır. Aynı anma çapına sahip pompa tipleri kombinasyon olarak ele alınmıştır. Pompa tiplerinin karşılaştırılmasında kuyu su seviyesi düşüm değerlerine varyans analizi ve Tukey testi yapılmıştır. Deneme sonuçlarına göre, aynı tip pompaların anma çapları arttıkça kuyu su seviye düşümü genel olarak artmıştır. Pompa kombinasyonlarının $\left(\mathrm{D}_{1}-\mathrm{M}_{1}, \mathrm{D}_{2}-\mathrm{M}_{2}, \mathrm{D}_{3}-\mathrm{M}_{3}\right)$ tamamın da pompa tipleri arasındaki kuyu su seviyesi düşüm değerleri istatistiki açıdan önemli bulunmuştur ( $\mathrm{p}<0.01)$. Genel olarak dalgıç pompalarda milli pompalara göre daha fazla düşüm gerçekleşmiştir. $\mathrm{D}_{1}-\mathrm{M}_{1}$ pompa tipinde gürültü seviyesi sırasıyla 74.04-73.07 $\mathrm{dBA}, \mathrm{D}_{2}-\mathrm{M}_{2}$ pompa tipinde 76.64-78.91 dBA ve $\mathrm{D}_{3}-\mathrm{M}_{3}$ pompa tipinde ise 72.24-80.12 dBA olarak ölçülmüştür. Pompa anma çap1 arttıkça milli pompalar daha fazla gürültülü çalışmıştır. Tüm debi değerlerinin ortalamasında, $\mathrm{D}_{2}-\mathrm{M}_{2}$ pompa tiplerinde dalgıç pompa milli pompaya göre \%8.4 daha fazla elektrik enerjisi çekerken, $\mathrm{D}_{3}-\mathrm{M}_{3}$ pompa tiplerinde ise milli pompa dalgıç pompaya göre \% 8.3 daha fazla elektrik enerjisi çekmiştir. Pompa tiplerinin tamamında dalgıç pompada milli pompaya göre daha fazla toplam dinamik yükseklik değeri elde edilmiştir. Genel olarak aynı çalışma şartlarının sağlandığı durumlarda pompaların sağladığı toplam dinamik yükseklik ve şebekeden çektikleri güç bakımından dalgıç pompaların tercih edilmesi uygun olacaktır.

Anahtar Kelimeler: Dalgıç pompa, Milli pompa, Düşüm, Gürültü seviyesi, Toplam dinamik yükseklik.

\section{Comparison of Some Pumping Parameters in Submersible and Vertical Shaft Deep Well Pumps}

\begin{abstract}
Agricultural irrigation activities are provided from underground and surface water resources. Two types of deep well pumps submersible and vertical shaft are used to bring the underground water resources to the surface. In the study, different flow rates of submersible pumps with an outer diameter of $150 \mathrm{~mm}\left(\mathrm{D}_{1}\right), 175 \mathrm{~mm}\left(\mathrm{D}_{2}\right)$, and $200 \mathrm{~mm}\left(\mathrm{D}_{3}\right)$ and shaft type deep well pumps with an outer diameter of $150 \mathrm{~mm}\left(\mathrm{M}_{1}\right), 175 \mathrm{~mm}\left(\mathrm{M}_{2}\right)$ and $200 \mathrm{~mm}\left(\mathrm{M}_{3}\right)$, the aimed to compare the effects on the well water level drop, noise level, power drawn from the network and total dynamic height values. According to the trial results, as the nominal diameters of the same type pumps increased, the well water level drop generally increased. In all pump combinations $\left(\mathrm{D}_{1}-\mathrm{M}_{1}, \mathrm{D}_{2}-\mathrm{M}_{2}, \mathrm{D}_{3}-\mathrm{M}_{3}\right)$, well water level drop values among pump types were found to be statistically significant $(\mathrm{p}<0.01)$. In general, more reduction has been realized in submersible pumps compared to vertical shaft pumps. The noise level was measured as 76.64-78.91 dBA in the $\mathrm{D}_{1}-\mathrm{M}_{1}$ pump type, 76.64-78.91 dBA in the $\mathrm{D}_{2}-\mathrm{M}_{2}$ pump type and 72.24-80.12 dBA in the $\mathrm{D}_{3}-\mathrm{M}_{3}$ pump type, respectively. As the pump nominal diameter increased, the vertical shaft pumps worked with louder noise. In the average of all flow rates, in $\mathrm{D}_{2}-\mathrm{M}_{2}$ pump types, the submersible pump attracted $8.4 \%$ more electrical energy than the vertical shaft pump. In $\mathrm{D}_{3}-\mathrm{M}_{3}$ pump types, the vertical shaft pump attracted $8.3 \%$ more electrical energy than the submersible pump. In all pump types, a higher total dynamic head value was obtained in the submersible pump compared to the national pump. In general, when the same operating conditions are met, it will be appropriate to choose submersible pumps in terms of the total dynamic head provided by the pumps and the power drawn from the network.
\end{abstract}

Keywords: Submersible, Vertical shaft pump, Drawdown, Noise level, Total dynamic head.

* Corresponding Author: nuriorhan $@$,selcuk.edu.tr 


\section{Giriş}

Tarımsal sulama faaliyetleri yer altı ve yer üstü su kaynaklarından sağlanmaktadır. Türkiye'nin yıllık su kullanım miktar1 57 milyar $\mathrm{m}^{3}$ olup; bunun \% 77'si sulamada, geriye kalan kısmı ise içme-kullanma suyu, sanayi suyu ihtiyaçlarının karşılanmasında kullanılmaktadır. Diğer yandan, Türkiye'nin yıllık su kullanım miktarının 16.62 milyar $\mathrm{m}^{3}$ 'ü yer altı su kaynaklarından sağlanmaktadır. Yer altı su kullanım miktarının \% 67.4'ü ise sulama amaçlı kullanılmaktadır (Anonim, 2019).

Yer altı su kaynaklarını yeryüzüne çıkarabilmek için düşey milli ve dalgıç olmak üzere iki tip derin kuyu pompası kullanılmaktadır (Culver ve Rafferty, 1998; Gölcü, 2002; Kalkat ve Veli, 2019).

Dalgıç pompalar ile düşey milli pompalar arasındaki temel fark tahrik elemanının yerleştirildiği konumdur. Dalgıç pompa, su altında çalışmaya uygun elektrik motoruna monte edilmesinden meydana gelmiştir. Pompa miline güç aktarımı, özel olarak tasarlanmış yataklardan dalgıç motor aracılığ ile alttan aktarılır (Gölcü, 2002). Düşey milli pompalarda ise pompa miline güç aktarımı kuyu başından-yukarıdan sağlanır. Burada motor yeryüzündedir; pompa ise yeryüzünden aşağıya istenilen seviyeye kadar indirilebilir (Güneş ve Konuralp, 1998). Pompa tahrik elemanı olarak içten yanmalı motor da kullanılmaktadır. Düşey milli pompaların mil kesme, şanzıman bakımı, montajın zor olması ve gürültülü çalışması dezavantaj oluşturmaktadır.

Santrifüj pompaların çok kademeli olması tek kademelilere göre pompa gövdesinin toplam uzunluğunu etkiler (Zhou ve ark., 2018). Tek kademeli pompanın basma yüksekliği çok düşükse, toplam basma yüksekliğine (Zhou ve ark., 2014) ulaşmak için pompa kademeleri artırılmalıdır. Böyle bir durumda, pompa gövdesinin ve milin uzunluğunun uzatılması gerekir, bu da mekanik sıkıntılara ve kurulumun daha maliyet olmasına yol açar. Pompa tasarımındaki en önemli sorunlardan biri, hidrolik kayıpların nasıl azaltılacağı ve tek kademeli basma yüksekliğinin nasıl iyileştirileceğidir (Zhou ve ark., 2018). Yer altı sulamalarında kullanılan dalgıç ve milli tip pompaların aynı özelliklere sahip derin kuyu tasarımında hidrolik performansların karşılaştırılması pompa ve kuyu tasarımları için yol gösterecektir.

$\mathrm{Bu}$ çalışmada üç farklı anma çapına sahip dalgıç $\left(\mathrm{D}_{1}-\mathrm{D}_{2}-\mathrm{D}_{3}\right)$ ve milli pompa $\left(\mathrm{M}_{1}-\mathrm{M}_{2}-\mathrm{M}_{3}\right)$ tiplerinin, farklı debi değerlerinde $(\mathrm{Q})$, kuyu su seviye düşümüne $(\Delta)$, gürültü seviyelerine $(\mathrm{G})$, şebekeden çekilen güç $(\mathrm{N})$ ve toplam dinamik yükseklik (TDY) değerlerine etkileri karşılaştırılmıştır.

\section{Materyal ve Metot}

\subsection{Materyal}

Pompa denemeleri; Selçuk Üniversitesi, Ziraat Fakültesi, Tarım Makineleri ve Teknolojileri Mühendisliği Bölümü’nde Prof. Dr. Şinasi YETKIN Tarım Makineleri ve Teknolojileri Mühendisliği Uygulama Atölyesi'nde yapılan Derin Kuyu Test Ünitesi'nde yürütülmüştür. Test ünitesine ait genel ölçüler ve bazı derin kuyu terminolojik ifadeler Şekil 1'de verilmiştir.

Derin kuyu ile depo arasına çapı 4" ve 6" olan iki adet boru bağlanarak kuyunun alttan beslenmesi sağlanmıştır.

Deneylerde kullanılan dalgı̨̧ ve düşey milli pompalara ait bazı teknik özellikler Tablo 1'de verilmiştir. Pompaların tahrik edilmesi için kullanılan elektrik motorlarının teknik özellikleri ise Tablo 2'de verilmiştir.

Pompa deneme kombinasyonlarında $2000 \mathrm{~mm}$ uzunluğunda bir adet kolon borusu kullanılmıştır. Çalışmada kullanılan ölçüm aletlerinin bazı teknik özellikleri Tablo 3 'te verilmiştir.

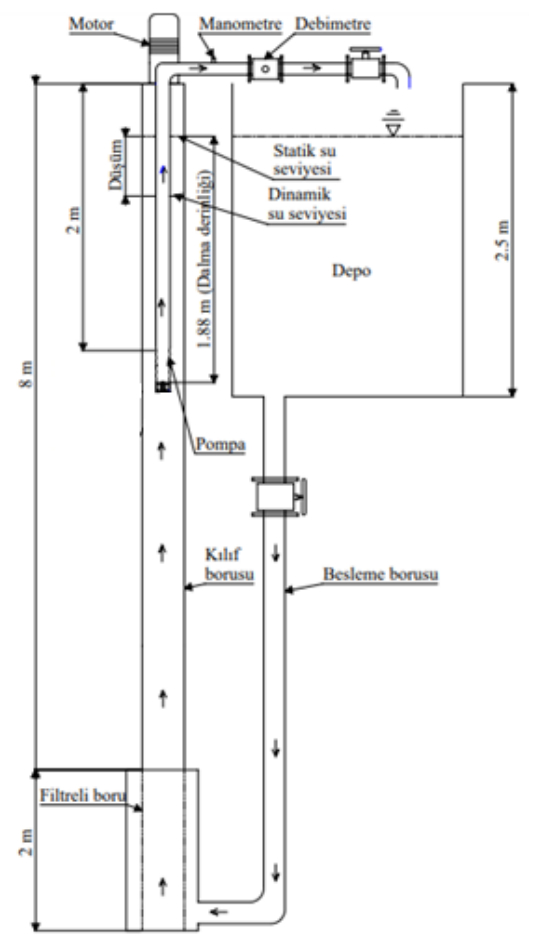

Şekil 1. Derin kuyu test ünitesinin genel ölçüleri ve görünüşü

Tablo 2. Motorlara ait bazı teknik özellikler

\begin{tabular}{l|l|l|l}
\hline Özellikleri & $\begin{array}{l}\text { Dalgıç } \\
\text { motor I }\end{array}$ & $\begin{array}{l}\text { Dalgıç motor } \\
\text { II }\end{array}$ & $\begin{array}{l}\text { Milli } \\
\text { motor }\end{array}$ \\
\hline Marka & Suver & Watermot & Siemens \\
\hline Tip & Dalgıç & Dalgı̨̧ & Asenkron \\
\hline Gü̧̧(kW) & 4 & 5.5 & 5.5 \\
\hline Gerilim (V) & 380 & 380 & 380 \\
\hline $\begin{array}{l}\text { Akım şiddeti } \\
\text { (A) }\end{array}$ & 9.2 & 13.6 & 11.1 \\
\hline $\begin{array}{l}\text { Devir sayıs1 } \\
\text { (d/d) }\end{array}$ & 2869 & 2780 & 2910 \\
\hline Frekans (Hz) & 50 & 50 & 50 \\
\hline $\begin{array}{l}\text { Güç faktörü } \\
\text { cos } \phi)\end{array}$ & 0.86 & 0.84 & 0.85 \\
\hline
\end{tabular}

Seçilen dalgıç pompaların güç gereksinimi küçük olduğundan motorların anma çapı da 6" ölçüsündedir. Oysa çalışmada kullanılan dalgıç pompalar 7" ve 8" dış çapa sahiptir. $\mathrm{D}_{1}$ 6"'lik pompasının tahrikinde dalgıç motor I kullanılmış; 7" ve 8"'lik dalgıç pompaların tahrik edilmesinde ise, dalgıç motor II kullanılmıştır. Çalışmada, 7" ve 8"'lik pompaların çapları ile motor çaplarını ayarlanmak için 7" anma çapındaki dalgıç pompada 7"'lik, 8" dalgıç pompada ise 8"'lik kılıf (kovan) kullanılmıştır. Bunun sebebi ise pompa çapı ile motor çapını birbirine eşitleyerek, pompalar arasında aynı fiziksel şartları oluşturmaktır. 
European Journal of Science and Technology

Tablo 1. Dalgıç ve milli pompaların pompa gruplarına ait bazı teknik özellik ve ölçüleri

\begin{tabular}{|c|c|c|c|c|c|c|}
\hline Teknik özellikler & Dalgıç pom & oyutları & & Milli pomp & boyutları & \\
\hline Pompa diş çapı (mm) & $78(6 ")$ & $105(7 ")$ & $128(8 ")$ & 78 & 105 & 128 \\
\hline Pompa gövde malzemesi & Pik & Pik & Pik & Pik & Pik & Pik \\
\hline Pompa çark malzemesi & Pirinç & Pirinç & Pirinç & Pirinç & Pirinç & Pirinç \\
\hline Pompa mil malzemesi & $\begin{array}{l}\text { Paslanmaz } \\
\text { çelik }\end{array}$ & $\begin{array}{l}\text { Paslanmaz } \\
\text { çelik }\end{array}$ & $\begin{array}{l}\text { Paslanmaz } \\
\text { çelik }\end{array}$ & $\begin{array}{l}\text { Paslanmaz } \\
\text { çelik }\end{array}$ & $\begin{array}{l}\text { Paslanmaz } \\
\text { çelik }\end{array}$ & $\begin{array}{l}\text { Paslanmaz } \\
\text { çelik }\end{array}$ \\
\hline Su giriș alanı $\left(\mathrm{mm}^{2}\right)$ & 7200 & 9000 & 10800 & 7200 & 9000 & 10800 \\
\hline Pompa mili çapı $(\mathrm{mm})$ & 25 & 25 & 30 & 25 & 25 & 25 \\
\hline Pompa kademe sayıs1 & 2 & 1 & 1 & 2 & 1 & 1 \\
\hline Klerens açıklığ 1 (mm) & 4.5 & 4.5 & 4.5 & 4.5 & 4.5 & 4.5 \\
\hline Kanat sayıs1 (adet) & 5 & 7 & 6 & 5 & 5 & 5 \\
\hline Kanat kalınlığ1 $(\mathrm{mm})$ & 5 & 5 & 5 & 5 & 5 & 5 \\
\hline Çark çıkış çapı (mm) & 94.5 & 140 & 150 & 93.5 & 136 & 150 \\
\hline Çark çıkış genişliği (mm) & 15 & 16 & 20 & 15 & 16 & 17.5 \\
\hline
\end{tabular}

Tablo 3. Kullanılan ölçme aletlerinin bazı teknik özellikleri

\begin{tabular}{|c|c|}
\hline $\begin{array}{l}\text { Ekipman } \\
\text { cinsi }\end{array}$ & Bazı teknik özellikleri \\
\hline Debimetre & $\begin{array}{l}\text { S MAG } 100 \text { TỉP, DN } 80-100-125 \text { flanş } \\
\text { bağlantılı elektromanyetik debimetre, } 220 \mathrm{~V} \\
\text { beslemeli dijital göstergeli, anlık debi, yüzde } \\
\text { akış ve toplam gösterimli. Ayarlanabilir } 4-20 \\
\text { mA plus ve frekans çıkışl. Ölçüum hatası } \\
\% 0.5\end{array}$ \\
\hline Manometre & $\begin{array}{l}\text { WíKA, 0-10 bar, Alttan Bağlantılı, 4-20 mA } \\
\text { çıkışl.. }\end{array}$ \\
\hline Seviye ölçer & $\begin{array}{l}\text { Hydrotechnik marka, } 010 \text { tip/ } 1.5 \mathrm{~V}, 150 \text { m’lik } \\
\text { ölçeklendirilmiş kablolu, ses ve 1şı ikazlı } \\
\text { tip. }\end{array}$ \\
\hline $\begin{array}{l}\text { Gürülttü } \\
\text { ölçer }\end{array}$ & $\begin{array}{l}\text { CT-2012 model, giriş } 4 \mathrm{~mA} \text {, DC 24V güç } \\
\text { kaynağı çıkış göstergesi. Ölçüm aralığı: } 30-80 \\
\mathrm{~dB}, 50-100 \mathrm{~dB}, 80-130 \mathrm{~dB} \text {, çıkış 4-20 mA, } \\
90-260 \mathrm{ACV} 50 \mathrm{~Hz} / 60 \mathrm{~Hz} \text {, Çalışma sıcaklığ } \\
0-50{ }^{\circ} \mathrm{C}\end{array}$ \\
\hline $\begin{array}{l}\text { Sicaklık } \\
\text { sensörleri }\end{array}$ & $\begin{array}{l}\text { Turck marka, } 10-24 \text { VDC, }-50 \ldots 100{ }^{\circ} \mathrm{C}, 4-20 \\
\text { mA çıkış. }\end{array}$ \\
\hline Bilgisayar & Asus intel core i7. \\
\hline
\end{tabular}

\subsection{Yöntem}

Denemelerde debi, pozitif basınç, şebekeden çekilen güç, akım şiddeti, gürültü, sıcaklıklar gibi fiziksel büyüklüklerin kaydedilmesi için yazılım ve otomasyon sistemi kullanılmıştır. Sensörler yardımıyla alınan bilgiler merkezi bir veri toplama kartı üzerinden kablosuz (Bluetooth) olarak bilgisayara aktarılmıştır. Kuyu su seviye ölçümleri, pompanın ilgili debide belli bir düzene girdikten sonra seviye ölçer ile ölçülerek kayıt dosyasına el ile girilmiştir.
Pompalar optimum çalışma devrinde ve her bir pompa değişik debi aralıklarında kuyu düşüm seviyeleri, gürültü seviyesi, şebekeden çekilen güç ve çıkış basınçları ölçülmüştür. Pompa belirlenen herhangi bir debi değerinde çalıștırılarak ilk değerler kayıt altına alındıktan sonra diğer debi değerinden ölçümler alınmıştır. Çalışmaya ait deneme planı Şekil 2'de verilmiştir.

Pompa denemeleri $1880 \mathrm{~mm}$ sabit hidrolik yük altında gerçekleşmiştir. Pompa işletme karakteristiklerinin ölçülmesinde ve yapılan hesaplamalarda ilgili standartlar ve literatür dikkate alınmıştır (Tezer, 1978; Baysal, 1979; Atmaca, 1998; Karassik ve ark., 2001; Anonim, 2002; Çalışır, 2009). Gürültü seviyesi, gürültü ölçme cihazı ile kule kumanda merkezi platformundan pompa kolon ile kapalı teçhiz borusu arasındaki boşluktan ölçülmüştür (Čdina, 2003; Čudina ve Prezelj, 2009; Maxime ve Chen Li, 2015).

$\mathrm{D}_{1}-\mathrm{M}_{1}$ kombinasyonunda farklı motor güçleri kullanıldığ için pompaların şebekeden çektikleri güç bakımından karşılaştırılmaları yapılmamıştır. Pompa tiplerinin düşüm üzerine olan etkisinin istatistiki bakımından önemli olup olmadığı konusundaki varyans analizleri yapılmıştır.

Denemeler süresince ortalama ortam sicakl $l$ ğ $17^{\circ} \mathrm{C}$ ve suyun ortalama sıcaklığı ise $14{ }^{\circ} \mathrm{C}$ olarak ölçülmüsstür. Pompa denemelerin hepsi $1880 \mathrm{~mm}$ sabit hidrolik yük altında ve $890 \mathrm{~mm}$ statik su seviyesinde başlanmıştır. Pompaların farklı debi değerlerinde gerçekleşen düşüm değerleri $(\Delta)$, gürültü seviyeleri (G) ve toplam dinamik yükseklik (TDY) değerleri ölçülmüss ve karşılaştırılmıştır. 


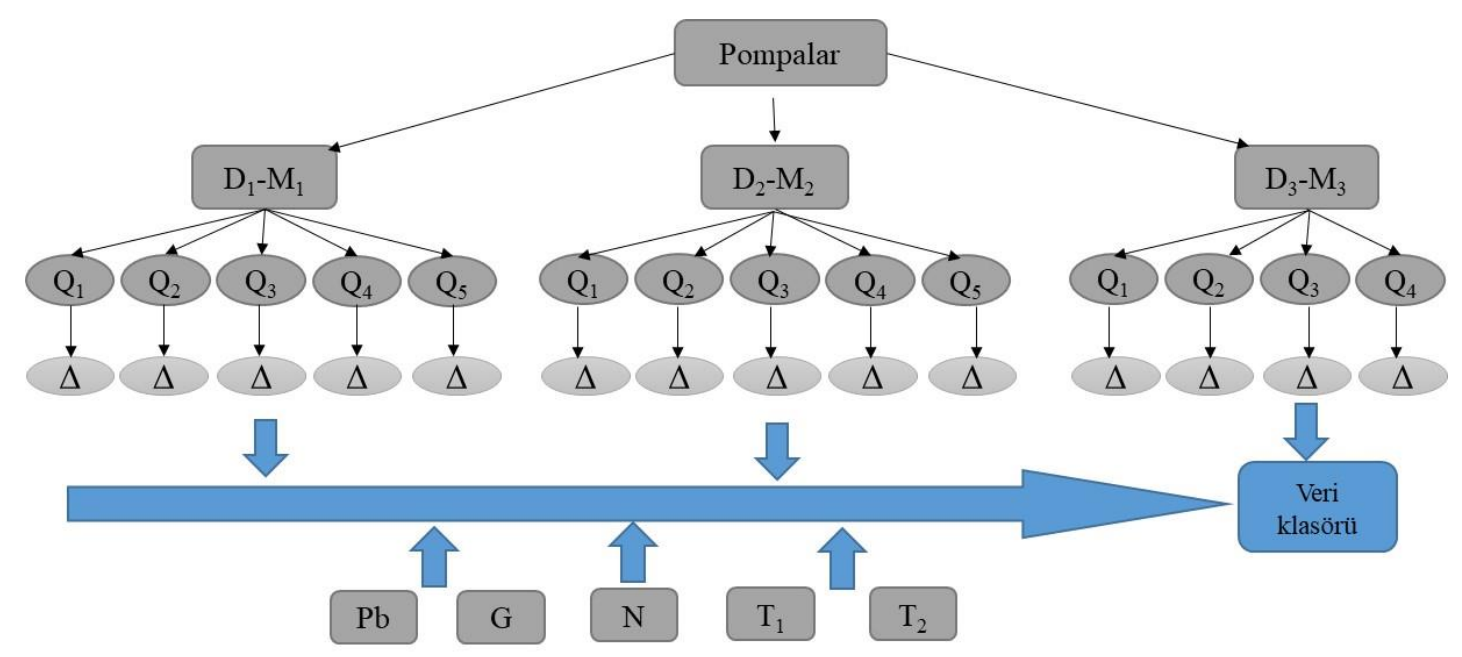

Şekil 2. Deneme deseni

\section{Araştırma Sonuçları ve Tartışma}

\subsection{Pompa tiplerinin düşüm üzerine etkisi}

Kuyu besleme borularının tam açık olduğu konumda dalgıç ve milli pompalarının debi-düşüm ilişkisi Şekil 3 'te verilmiştir.

\section{$\operatorname{Debi}\left(\mathrm{m}^{3} \mathrm{~h}^{-1}\right)$}

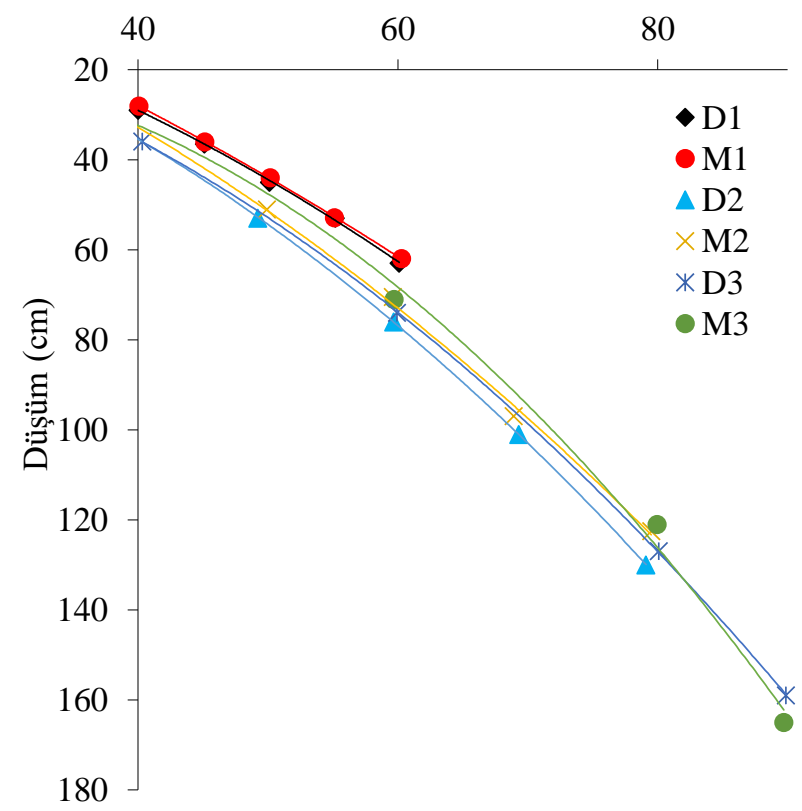

\section{Şekil 3. Pompaların debi ile düşüm arasındaki ilişkisi}

Pompa tiplerinin her birinde debi attıkça düşüm değerleri yükselmiştir. Pompa anma çapı arttıkça düşüm seviyeleri genel olarak yükselmiştir. Örneğin $\mathrm{D}_{1}, \mathrm{D}_{2}$ ve $\mathrm{D}_{3}$ pompa tiplerinde $40 \mathrm{~m}^{3} \mathrm{~h}^{-1}$ debi değerinde sırası ile $29 \mathrm{~cm}, 34 \mathrm{~cm}$ ve $36 \mathrm{~cm}$ düşüm gerçekleşmiştir. $\mathrm{D}_{1}-\mathrm{M}_{1}, \mathrm{D}_{2}-\mathrm{M}_{2}$ ve $\mathrm{D}_{3}-\mathrm{M}_{3}$ pompa tiplerinde farklı debi değerlerinde meydana gelen düşüm seviyelerine yapilan varyans analiz sonuçları Tablo 4 'te verilmiştir.
Tablo 4. Dalgıç $\left(D_{1}-D_{2}-D_{3}\right)$ ve Milli $\left(M_{1}-M_{2}-M_{3}\right)$ pompa tipi ve debinin, düşüm değerlerine ait varyans analiz sonuçları

\begin{tabular}{c|l|l|l}
\hline \multirow{5}{*}{$\mathrm{D}_{1}-\mathrm{M}_{1}$} & & SD & P \\
\cline { 2 - 4 } & PT(Pompa tipi) & 1 & $0.002^{* *}$ \\
\cline { 2 - 4 } & Q (Debi) & 4 & $0.000^{* *}$ \\
\cline { 2 - 4 } & PT x Q & 4 & $0.337^{*}$ \\
\cline { 2 - 4 } & Hata & 20 & --- \\
\cline { 2 - 4 } & Genel & 29 & --- \\
\hline \multirow{5}{*}{$\mathrm{D}_{2}-\mathrm{M}_{2}$} & & SD & P \\
\cline { 2 - 4 } & PT(Pompa tipi) & 1 & $0.000^{* *}$ \\
\cline { 2 - 4 } & Q (Debi) & 4 & $0.000^{* *}$ \\
\cline { 2 - 4 } & PT x Q & 4 & $0.000^{*}$ \\
\cline { 2 - 4 } & Hata & 20 & --- \\
\cline { 2 - 4 } & Genel & 29 & --- \\
\hline \multirow{5}{*}{$\mathrm{D}_{3}-\mathrm{M}_{3}$} & & SD & P \\
\cline { 2 - 4 } & PT(Pompa tipi) & 1 & $0.000^{* *}$ \\
\cline { 2 - 4 } & Q (Debi) & 4 & $0.000^{* *}$ \\
\cline { 2 - 4 } & PT x Q & 4 & $0.000^{*}$ \\
\cline { 2 - 4 } & Hata & 20 & --- \\
\cline { 2 - 4 } & Genel & 29 & --- \\
\hline
\end{tabular}

Tablo 4 incelendiğinde, $\mathrm{D}_{1}-\mathrm{M}_{1}$ kombinasyonlarının debi ve pompa tipinin tekli olarak düşüm üzerine etkisi istatistiki açıdan çok önemli $(p<0.01)$ olduğu ikili interaksiyon ise istatistiki bakımdan önemsiz bulunmuştur $(\mathrm{p}>0.05) . \mathrm{D}_{2}-\mathrm{M}_{2}$ ve $\mathrm{D}_{3}-\mathrm{M}_{3}$ kombinasyonlarında ise debi ve pompa tipinin tekli ve ikili interaksiyonun her ikisinin de düşüm üzerinde istatistiki açıdan çok önemli $(\mathrm{p}<0.01)$ olduğu görülmüştür.

Denemeleri yapılan $\mathrm{D}_{1}-\mathrm{M}_{1}, \mathrm{D}_{2}-\mathrm{M}_{2}$ ve $\mathrm{D}_{3}-\mathrm{M}_{3}$ pompaların birbirleri arasında karşılaştırmaları sonuçları Tukey testi yapılarak Tablo 5 'te sonuçlara ait değerler verilmiştir. 
Tablo 5. Dalgıç ( $\left.D_{I}-D_{2}-D_{3}\right)$ ve Milli $\left(M_{1}-M_{2}-M_{3}\right)$ pompa tipi ve debiler arasındaki farklılara göre elde edilen düşüm değerlerine (cm) uygulanan Tukey testi sonuçları

\begin{tabular}{|c|c|c|c|c|}
\hline \multirow{7}{*}{$\mathrm{D}_{1}-\mathrm{M}_{1}$} & $\mathrm{Q}$ & $\mathrm{D}_{1}$ & $\mathrm{M}_{1}$ & Q- $\Delta$ \\
\hline & 40 & $29.00^{\mathrm{e}}$ & $28.13^{\mathrm{e}}$ & $28.57^{\mathrm{e}}$ \\
\hline & 45 & $36.33^{\mathrm{d}}$ & $36.00^{\mathrm{d}}$ & $36.17^{\mathrm{d}}$ \\
\hline & 50 & $45.00^{c}$ & $44.00^{\mathrm{c}}$ & $44.50^{c}$ \\
\hline & 55 & $53.00^{\mathrm{b}}$ & $53.00^{\mathrm{b}}$ & $53.00^{\mathrm{b}}$ \\
\hline & 60 & $62.90^{\mathrm{a}}$ & $61.93^{\mathrm{a}}$ & $62.42^{\mathrm{a}}$ \\
\hline & PT- $\Delta$ & $45.25^{\mathrm{a}}$ & $44.61^{b}$ & \\
\hline \multirow{7}{*}{$\mathrm{D}_{2}-\mathrm{M}_{2}$} & $\mathrm{Q}$ & $\mathrm{D}_{2}$ & $\mathrm{M}_{2}$ & Q- $\Delta$ \\
\hline & 40 & $34.00^{1}$ & $33.00^{1}$ & $33.50^{\mathrm{e}}$ \\
\hline & 50 & $53.17^{\mathrm{g}}$ & $51.17^{\mathrm{h}}$ & $52.17^{\mathrm{d}}$ \\
\hline & 60 & $76.00^{\mathrm{e}}$ & $70.33^{\mathrm{f}}$ & $73.17^{\mathrm{c}}$ \\
\hline & 70 & $101.00^{\mathrm{c}}$ & $97.00^{\mathrm{d}}$ & $99.00^{\mathrm{b}}$ \\
\hline & 80 & $129.83^{\mathrm{a}}$ & $122.5^{\mathrm{b}}$ & $126.17^{\mathrm{a}}$ \\
\hline & PT- $\Delta$ & $78.80^{\mathrm{a}}$ & $74.80^{\mathrm{b}}$ & \\
\hline \multirow{6}{*}{$\mathrm{D}_{3}-\mathrm{M}_{3}$} & $\mathrm{Q}$ & $\mathrm{D}_{3}$ & $\mathrm{M}_{3}$ & Q- $\Delta$ \\
\hline & 40 & $36.00^{\mathrm{g}}$ & $31.00^{\mathrm{h}}$ & $33.50^{\mathrm{d}}$ \\
\hline & 60 & $74.00^{\mathrm{e}}$ & $71.00^{\mathrm{f}}$ & $72.50^{c}$ \\
\hline & 80 & $127.00^{\mathrm{c}}$ & $120.83^{\mathrm{d}}$ & $123.92^{b}$ \\
\hline & 90 & $159.83^{\mathrm{b}}$ & $164.83^{\mathrm{a}}$ & $162.08^{\mathrm{a}}$ \\
\hline & PT- $\Delta$ & $99.08^{\mathrm{a}}$ & $96.92^{b}$ & \\
\hline
\end{tabular}

$\mathrm{D}_{1}-\mathrm{M}_{1}$ pompaları incelendiğinde pompa tipinde de debi arttıkça düşüm değerlerinin arttı̆̆ı görülmektedir. Sabit debi değerlerinde dalgıç pompanın neden olduğu düşüm, milli pompadan daha büyük tespit edilmiştir. Ancak bu durum tüm debi değerlerinde istatistiki bakımdan önemsiz çıkmışırı. $\mathrm{D}_{1}$ ile $\mathrm{M}_{1}$ pompa tipinin tüm debi değerlerinde elde edilen düşüm değerlerinin ortalamaları ise istatistiki olarak önemli bulunmuştur.

Pompa tipi ve düşüm değerleri $\mathrm{D}_{2}-\mathrm{M}_{2}$ pompalarında da debinin artmasına bağlı olarak düşüm değerlerinin de artmasına neden olmuştur. Sabit debi değerlerinde dalgıç pompanın neden olduğu düşüm, milli pompa göre daha büyük olduğu belirlenmiştir. Aynı zaman da bu durum $40 \mathrm{~m}^{3} \mathrm{~h}^{-1}$ debi değeri hariç diğer debi değerlerinde istatistiki bakımdan önemli olduğu görülmüsstür. Pompa tiplerinin tüm debi değerlerinde elde edilen en fazla düşüm değeri $78.8 \mathrm{~cm}$ ile $\mathrm{D}_{2}$ tipinde olmuş ve aralarındaki fark istatistiki olarak önemli çıkmıştır.

$\mathrm{D}_{3}-\mathrm{M}_{3}$ pompa tiplerinde elde edilen düşüm değerleri ortalamaları ve uygulanan Tukey testi sonuçlarını inceleyecek olursak; sabit debi değerlerinde $90 \mathrm{~m}^{3} \mathrm{~h}^{-1}$ debi değeri hariç diğerlerinde dalgıç pompanın neden olduğu düşüm, milli pompadan daha büyük olmuştur. Pompa tiplerinin tüm debi ortalamaları bakımından ise diğer pompalarda olduğu gibi dalgıç pompada en fazla düşüm $(99.08 \mathrm{~cm})$ gerçekleşmiştir.

Pompa tipleri bakımından dalgıç pompada milli pompaya göre daha fazla düşüm gerçekleşmiştir. Bunun sebebini dalgıç pompanın sabit kuyu teçhiz borusunda milli pompaya göre kuyu kesit alanını daha fazla daraltmasına bağlayabiliriz. Benzer sonuçları Ertöz (1996) de belirtmiş ve sebebini dalgıç pompanın kuyu teçhiz borusunu daraltmasından dolayı kuyudaki suyun pompaya giriş hızını artırmasına bağlamıştır. Kurt ve Çalışır (2017)'de çalışmalarında benzer pompalarda kuyunun üstten beslenmesi durumunda dalgıç pompalarda milli pompalara göre daha fazla düşüm elde ettiklerini bildirmişlerdir.

\subsection{Pompa Tiplerinin Gürültü Seviyesi Üzerine Etkisi}

Kuyu besleme borularının tam açık olduğu durumda, pompa tiplerinin farklı debilerde gürültü seviyesine (G) etkisi Şekil 4'de verilmiştir. 

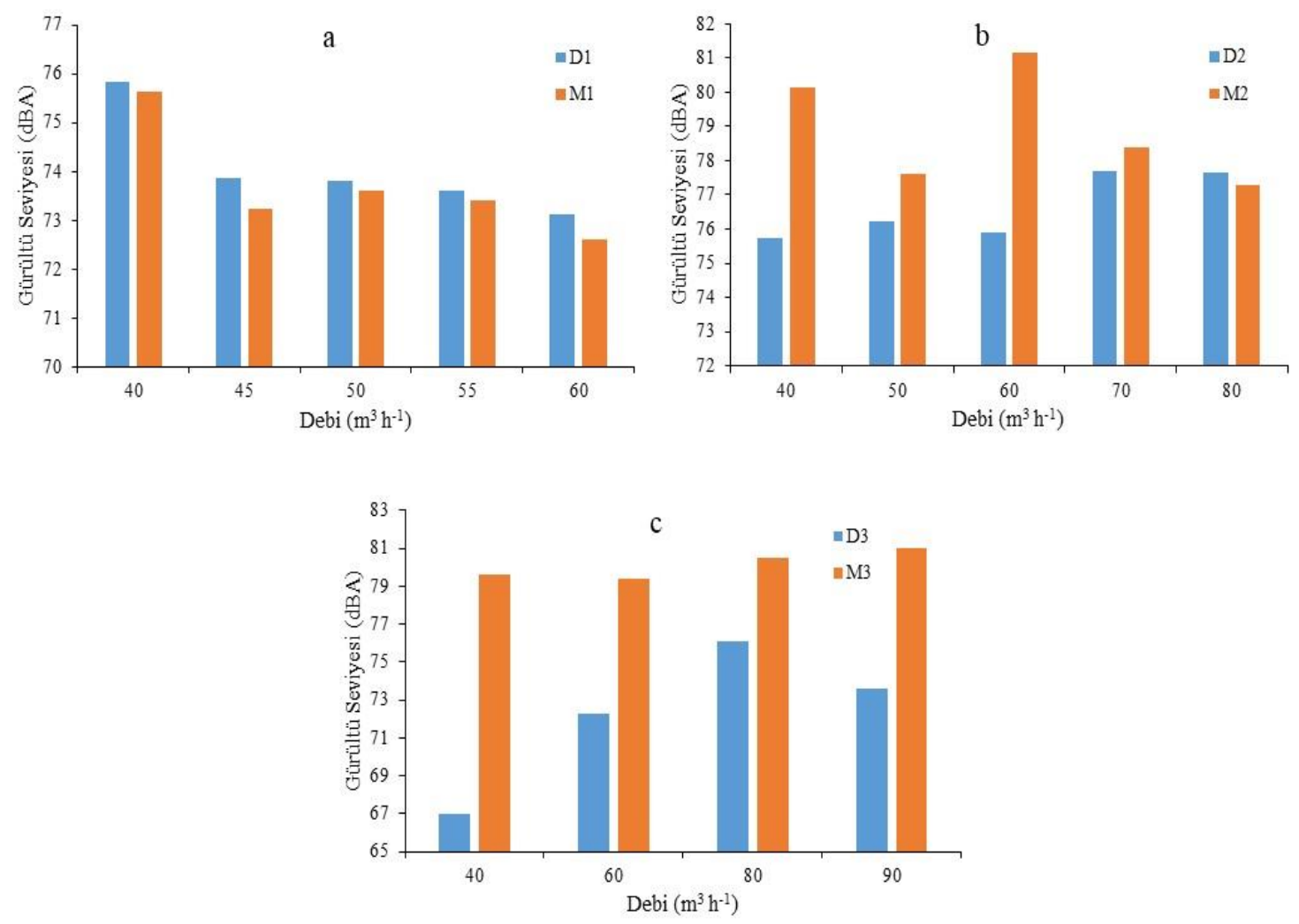

Şekil 4.Pompa tiplerinin farklı debilerde gürültü seviyesine etkisi

$D_{1}$ ve $M_{1}$ pompa tipinde en yüksek gürültü seviyesi $40 \mathrm{~m}^{3} \mathrm{~h}^{-1}$ debi değerinde elde edilmiştir (Şekil 4a). Pompa tipleri bakımından $\mathrm{D}_{1}$ ve $\mathrm{M}_{1}$ 'de gürültü seviyeleri ortalamaları sırası ile 74.04 ve $73.07 \mathrm{dBA}$ olarak bulunmuştur. $\mathrm{D}_{1}$ pompasının gürültü seviyesi $\mathrm{M}_{1}$ pompa tipine göre yüksek çıkmıştır.

$\mathrm{D}_{2}$ pompa tipinde en yüksek gürültü seviyesi $60 \mathrm{~m}^{3} \mathrm{~h}^{-1}$ debi değerinde elde edilirken, $D_{2}$ pompa tipinde ise $80 \mathrm{~m}^{3} \mathrm{~h}^{-1}$ debi değerinde en yüksek gürültü seviyesi elde edilmiştir (Şekil 4b). $D_{2}$ ve $M_{2}$ pompa tiplerinde gürültü seviyeleri ortalamaları sırasıyla 76.64 ve $78.91 \mathrm{dBA}$ olarak ölçülmüştür. $\mathrm{Bu}$ pompa tiplerinde milli pompanın gürültü seviyesi daha yüksek çıkmıştır.

$\mathrm{D}_{3}$ ve $\mathrm{M}_{3}$ pompa tiplerinde en yüksek gürültü seviyeleri sırasıyla $80 \mathrm{~m}^{3} \mathrm{~h}^{-1}$ ve $90 \mathrm{~m}^{3} \mathrm{~h}^{-1}$ debi değerlerinde elde edilmiştir. $D_{3}$ ve $M_{3}$ pompa tiplerinin gürültü seviyeleri ortalamaları ise sirası ile 72.24 ve $80.12 \mathrm{dBA}$ ' dir.

Pompa anma çapı arttıkça milli pompaların dalgıç pompalara göre daha fazla gürültülü çalıştığını söyleyebiliriz. Bu durumu milli pompaların motor grubunun su seviyesinin üstünde olmasına ve pompa kolon borusunun mil yataklarından, yatak sürtmelerinden gelen sese bağlayabiliriz.

\subsection{Pompa Tiplerinin Şebekeden Çekilen Güç Üzerine Etkisi}

$\mathrm{D}_{2}-\mathrm{M}_{2}$ ve $\mathrm{D}_{3}-\mathrm{M}_{3}$ pompa tipleri için $5.5 \mathrm{~kW}$ gücündeki dalgıç ve milli motor kullanıldığından bu iki grup arasında karşıllaştırma yapılmıştır (Şekil 5).
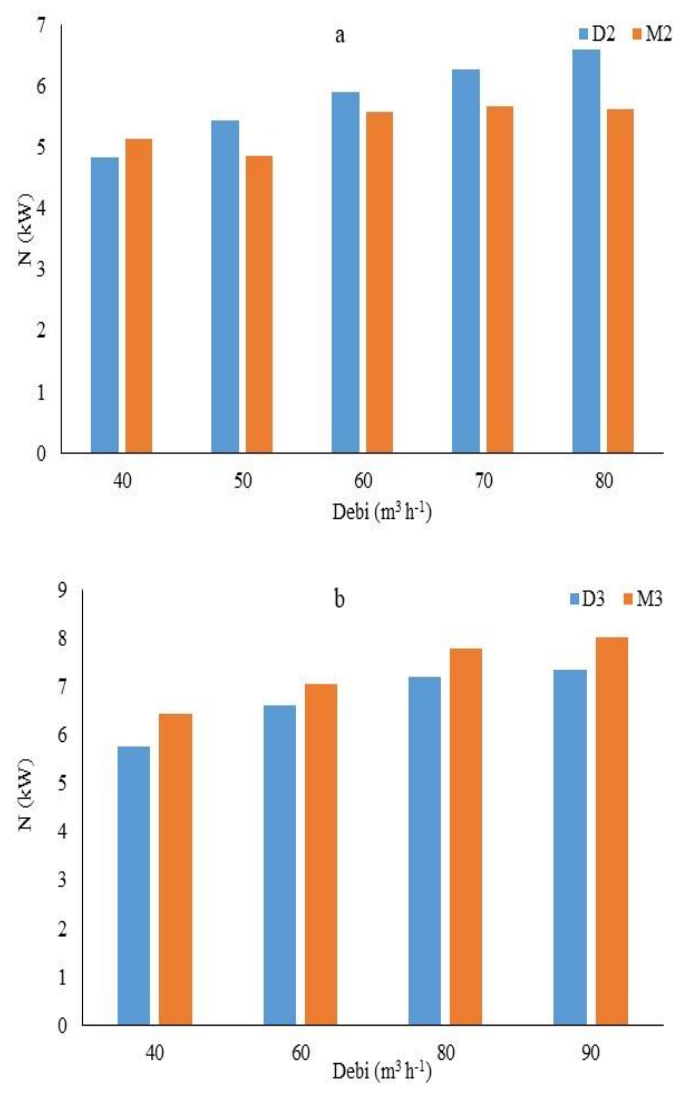

Şekil 5. Pompa tiplerinin farklı debilerde şebekeden çekilen güç üzerine etkisi 
Pompa tiplerinin her birinde genel olarak debi değeri artıkça şebekeden çekilen güç değeri de artış göstermiştir. $\mathrm{D}_{2}-\mathrm{M}_{2}$ pompa tiplerini incelediğimizde (Şekil 5a) dalgıç pompa $50 \mathrm{~m}^{3} \mathrm{~h}^{-1}$ debi değerinin dışında tüm debi değerlerinde milli pompaya göre fazla güç çekmiştir. $\mathrm{D}_{3}-\mathrm{M}_{3}$ pompa tiplerinde ise tüm debi değerlerinde milli pompa dalgıç pompaya göre daha fazla güç çekmiştir. $\mathrm{D}_{2}-$ $\mathrm{M}_{2}$ pompa tiplerinin tüm debi değerlerinde şebekeden çektikleri ortalama güç değeri dalgıç pompada $5.81 \mathrm{~kW}$ milli pompada 5.36 $\mathrm{kW}$ hesaplanmıştır. $\mathrm{D}_{3}-\mathrm{M}_{3}$ pompa tiplerinin şebekeden çektikleri ortalama güç değerleri ise dalgıç pompada $6.75 \mathrm{~kW}$, milli pompada $7.31 \mathrm{~kW}$ ölçülmüştür.

\subsection{Pompa Tiplerinin Toplam Dinamik Yükseklik (TDY) Üzerine Etkisi}

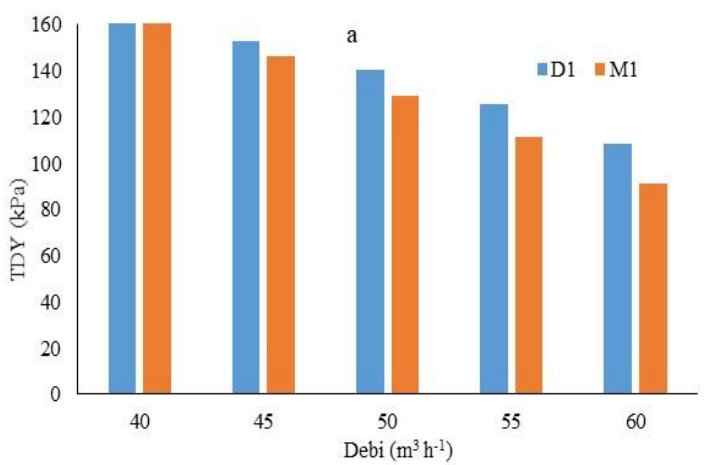

Kuyu besleme borularının tam açık olduğu konumda pompa tiplerinin farklı debilerde geliştirdikleri toplam dinamik yükseklikler Şekil 6'da verilmiştir.

Şekil 6 incelendiğinde tüm debi seviyelerinde dalgıç pompalarda milli pompalara göre daha yüksek TDY değerleri olduğu görülmektedir. Pompa tiplerinin tümün de debi arttıkça TDY düzeyleri azalmıştır. Pompaların TDY açısından aralarındaki en fazla fark $\mathrm{D}_{1}-\mathrm{M}_{1}$ pompalarında $17.4 \mathrm{kPa}$ ile $60 \mathrm{~m}^{3} \mathrm{~h}^{-1}$ debi değerinde gerçekleştiği tespit edilmiştir. $\mathrm{D}_{2}-\mathrm{M}_{2}$ pompalarında bu fark $16.9 \mathrm{kPa}$ ile $80 \mathrm{~m}^{3} \mathrm{~h}^{-1}$ debi değerinde ve $\mathrm{D}_{3^{-}}$$\mathrm{M}_{3}$ pompalarında ise $12.6 \mathrm{kPa}$ ile $60 \mathrm{~m}^{3} \mathrm{~h}^{-1}$ debi değerinde elde edilmiştir.
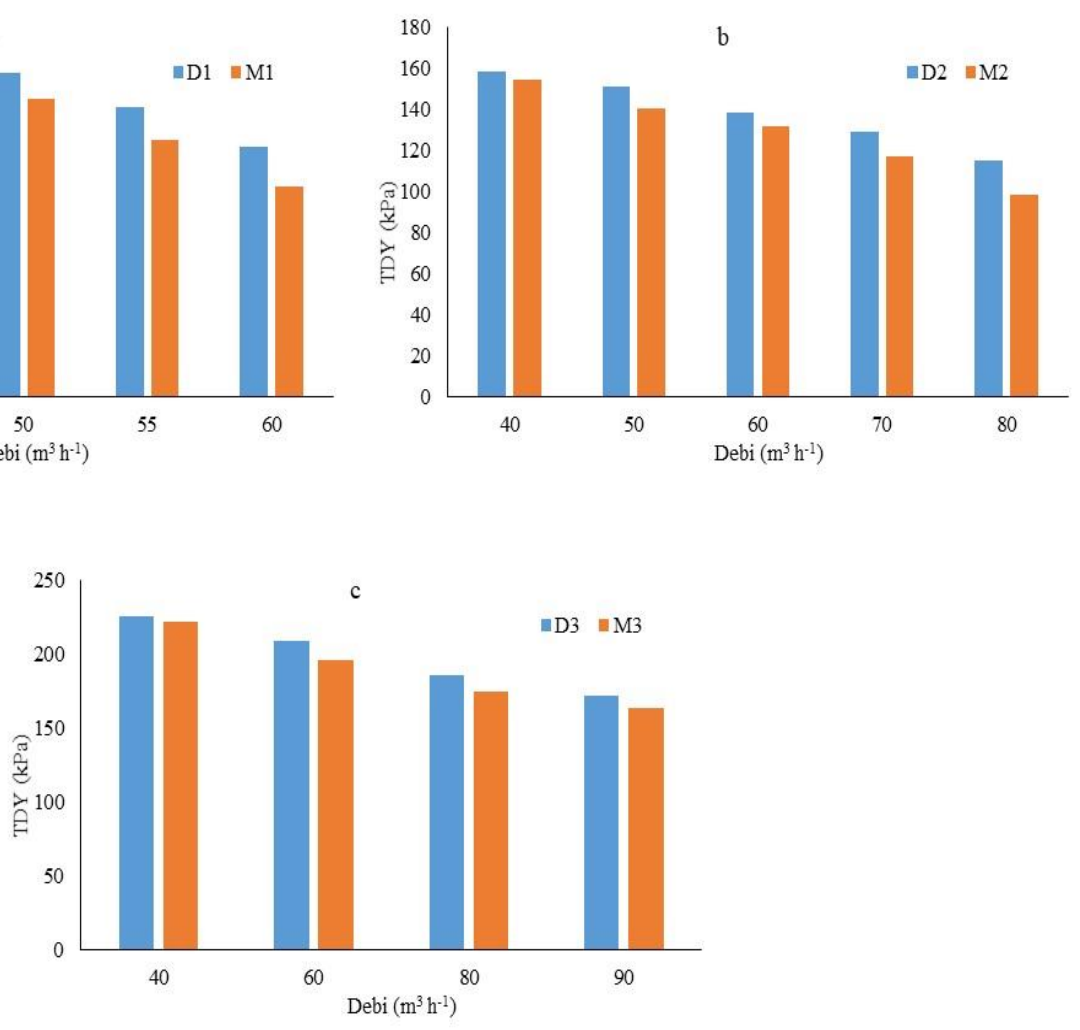

Şekil 6. Pompa tiplerinin toplam dinamik yükseklik (TDY) üzerindeki etkisi

\section{Sonuç}

Aynı tip pompalarda pompa anma çapının artması düşüm seviyelerinde genel olarak artış göstermiştir. Dalgıç pompaların tüm tiplerinde milli pompaya göre daha fazla düşüm gerçekleşmiştir. Dalgıç pompalarda motorun kuyu kesit alanını daraltmasının düşüm üzerine etkili olduğu ortaya çıkmıştır.

$\mathrm{D}_{1}-\mathrm{M}_{1}$ pompa tipinde dalgıç pompada, $\mathrm{D}_{2}-\mathrm{M}_{2}$ ve $\mathrm{D}_{3}-\mathrm{M}_{3}$ pompa tiplerinde ise milli pompalarda daha yüksek gürültü seviyesi çıkmıştır. Anma çapının artması milli pompaların dalgıç pompalara göre daha gürültülü çalışmasına sebep olmuştur.

Tüm debi değerlerinin ortalamasında, $\mathrm{D}_{2}-\mathrm{M}_{2}$ pompa tiplerinde dalgıç pompa milli pompaya göre \%8.4 daha fazla elektrik enerjisi çekerken, $\mathrm{D}_{3}-\mathrm{M}_{3}$ pompa tiplerinde ise milli pompa dalgıç pompaya göre \%8.3 daha fazla elektrik enerjisi çekmiştir. $\mathrm{D}_{2}-\mathrm{M}_{2}$ pompa tiplerinde şebekeden çektikleri güç bakımından milli pompanın kullanılmasının, $\mathrm{D}_{3}-\mathrm{M}_{3}$ pompa tipinde ise dalgıç pompanın kullanılması daha uygun olacaktır.

Pompa tiplerinin tamamında dalgıç pompada milli pompaya göre daha fazla toplam dinamik yükseklik değeri elde edildi.

Genel olarak değerlendirdiğimizde aynı çalışma şartlarında pompaların sağladığı toplam dinamik yükseklik ve şebekeden çektikleri güç bakımından dalgıç pompaların tercih edilmesi uygun olacaktır. Ayrıca pompaların ilk satın alma maliyeti ve işletmenin enerji gideri bakımından dalgıç pompalar tercih edilebilir.

\section{Teşekkür}

Bu çalışma, Türkiye Bilimsel ve Teknik Araştırma Kurumu (TÜBİTAK, Proje No: 213O140) tarafindan desteklenmiştir. Bu çalışmaya katkıda bulunan merhum Prof. Dr. Sedat ÇALIŞIR Hocamıza teşekkür ederiz. 


\section{Kaynakça}

Anonim, 2002. Rotodinamik Pompalar-Hidrolik Performans Kabul Deneyleri,Sınıf 1 ve Sınıf 2. Türk Standardları Enstitüsü, Ankara. TS EN ISO 9906.

Anonim, 2019. $2019 \quad$ Faliyet Raporu. http://www.dsi.gov.tr/docs/stratejik-plan/dsi-2019-faaliyetraporu.pdf?sfvrsn=2 (Erişim tarihi: 05.08.2020).

Atmaca, S., 1998. Dalgıç Pompalara Uygulanan Pompa Kabul Deneyleri, 3, Pompa Kongresi, 24-26 Eylül, İstanbul, s.10-15.

Baysal, K., 1979. Tam santrifüj pompalar: hesap, çizim ve konstrüksiyon özellikleri, İstanbul Teknik Üniversitesi, s. 24.

Čdina, M., 2003. Detection of cavitation phenomenon in a centrifugal pump using audible sound, Mechanical systems and signal processing, 17 (6), 1335-1347.

Čudina, M., Prezelj, J., 2009. Detection of cavitation in operation of kinetic pumps. Use of discrete frequency tone in audible spectra, Applied Acoustics, 70 (4), 540-546.

Culver, G., Rafferty, K. D., 1998. Well Pumps, Geo-Heat Center, pp 7-13.

Çalışır, S., 2009. 14. Bölüm Sulamada Pompaj Tesisleri, Tarım Makineleri, Edt: Gazanfer., E., Ankara: Nobel Yayın Dağıtım, s. 544.

Ertöz, A., 1996, Yer altı suları pompaj ekonomisi ve pompa seçimine etki eden faktörler. 2. Pompa Kongresi, 3-5 Nisan, s. 24-33.

Gölcü, M., 2002, Üç Kademeli Dalgıç Pompaların Performans Eğrilerinin İncelenmesi, Pamukkale Üniversitesi Mühendislik Bilimleri Dergisi, 8 (2), 149-154.

Güneş, M. T., Konuralp, O., 1998, Dik Türbin Pompaların Testleri ve Kabul Kriterleri. 3. Pompa Kongresi. 24-26 Eylül, İstanbul, s. $16-22$.

Kalkat, M., Veli, T., 2019, Dalgiç Pompalarda Yapay Sinir Ağlari Kullanilarak Deneysel Akış Analizi, Konya Mühendislik Bilimleri Dergisi, 7, 895-908.

Karassik, I. J., Messina, J. P., Cooper, P., Heald, C. C., 2001, Pump handbook, McGraw-Hill New York, pp. 1824

Kurt, M., Çalışır, S., 2017, Derin Kuyu Pompalarında Anma Çapının Kuyudaki Su Seviyesinin Düşümüne Etkisi, Selçuk Tarım Bilimleri Dergisi, 3 (2), 291-297.

Maxime, B., Chen Li, F., 2015, Cavitation effects in centrifugal pumps-A review, Int. Journal of Engineering Research and Application, 10, 8.

Tezer, E., 1978, Sulamada Pompaj Tesisleri (proje, seçim ve işletme yöntemleri), Cilt 1-2-3. Çukurova Üniversitesi Ziraat Fakültesi Yayınları, Adana.

Zhou, L., Shi, W., Lu, W., Hu, B., and Wu, S., 2012, Numerical investigations and performance experiments of a deep-well centrifugal pump with different diffusers, Journal of Fluids Engineering, 134, (7).

Zhou, L., Bai, L., Shi, W., Li, W., Wang, C., and Ye, D., 2018, Numerical analysis and performance experiment of electric submersible pump with different diffuser vanes number. Journal of The Brazilian Society of Mechanical Sciences and Engineering, 40(2), 1-11. 